\title{
LANDSLIDE DETECTION BY INDICES OF LIDAR POINT-CLOUD DENSITY
}

\author{
Jin-King Liu ${ }^{* 1}$, Wei-Chen Hsu ${ }^{* 1}$, Mon-Shieh Yang ${ }^{* 2}$, Yu-Chung Shieh ${ }^{* 3}$, Tian-Yuan Shih ${ }^{* 4}$ \\ ${ }^{* 1}$ National Chiao-Tung University and Industrial Technology Research Institute; \#195, Chunghsing \\ Road Sec. 4, Hsinchu County 31040, Taiwan.jkliu@itri.org.tw \\ *2 National Cheng Kung University; Tainan City 70101, Taiwan. bermudagras@msn.com \\ ${ }^{* 3}$ Central Geological Survey, MOEA; Taipei County 23568, Taiwan. hsiehyc@moeacgs.gov.tw \\ ${ }^{* 4}$ National Chiao-Tung University; Hsinchu City 30010, Taiwan. tyshih@mail.nctu.edu.tw
}

\begin{abstract}
The deliverables of an airborne LiDAR survey usually include all points, ground points, digital surface models (DSM) and digital elevation models (DEM). Indices of point clouds tested in this study include density of all points, density of ground points, density of only returns, and density of multiple returns. Shallow landslides are the most common landslides triggered by torrential rainfalls and explicit fresh scars after rainfall events. Multiple returns in forest area give the possibility of differentiating landslide scars from vegetated lands. Classification results from the indices derived from these four kinds of densities are verified by the result obtained by manual interpretation of the derived nDSM images. The experiment is carried out using the dataset obtained in I-Lan County after Typhoon Kalmaegi on 17 July 2008. The results show that a proper definition of the parameters for the indices is most critical for the detection of shallow landslides.
\end{abstract}

Index Terms - Natural disaster, remote sensing, Image shape analysis, Object recognition

\section{INTRODUCTION}

Airborne LiDAR mapping technology is capable of collecting a large volume and high density of discrete points with a height accuracy within $0.15 \mathrm{~m}$ and horizontal accuracies within 1/1000th of the flight height. Basic products of airborne LiDAR include all points, ground points, digital elevation model (DEM), and digital surface model (DSM). The former two are vectors of discrete points and the later two are interpolated raster grids of the discrete points of the former two. The DEM and DSM grids are commonly used for subsequent applications whereas point clouds are rarely used for subsequent analysis. LiDAR discrete points are worthy of a further study due to the fruitful information adhered with the attributes of individual points. Point density has been used as an important indicator of DEM/DSM quality [1][2][3][4]. An understanding of the forest closure and crown density can be obtained by inspection of the point-density distribution of point clouds [5][6][7]. Therefore, point density derived from specific properties of point clouds can be used to explore the possibility of extracting landslide information from point clouds. Landslides are common threatens in Taiwan because the physiographical environments of heavy rainfalls and active tectonic movements. Visual interpretation of shaded-relief image derived from DEM is usually adopted by geologists whereas other LiDAR products have not been commonly applied. In this paper, possible derived indices from point clouds are discussed first and then experiments of selected indices are made to find out the most descriptive ones for landslide detection.

\section{EXPERIMENT SITE AND LIDAR DATA}

The study area is located in I-Lan County of northeastern Taiwan, on the track of the Typhoon Kalmaegi attacked Taiwan on July 16th 18th, 2008, about nine month after Typhoon Krosa on October 4th, 2007 in this area. The dataset for the experiment was taken on 4th November, 2008 after Typhoon Kalmaegi. In general, the accuracy of bare grounds checked in the field is about $0.15 \mathrm{~m}$. An area covering $2 \mathrm{~km}$ by $2 \mathrm{~km}$ is selected for the experiment. The overall point density of the study area is 2.75 points $/ \mathrm{m}^{2}$ with ground point density of 0.75 points $/ \mathrm{m}^{2}$ (TABLE 1 ).

TABLE 1 SOME STATISTICS OF THE LIDAR DATA USED IN THIS STUDY

\begin{tabular}{|c|c|c|c|c|}
\hline Type of points & All points & Ground points & Only-echoes points & Multiple-echoes points \\
\hline Total number of points & $12,142,434$ & $3,320,615$ & $5,789,148$ & $6,353,286$ \\
\hline
\end{tabular}




\begin{tabular}{|c|c|c|c|c|}
\hline Average point density $\left(\right.$ points $\left./ \mathrm{m}^{2}\right)$ & 2.75 & 0.75 & 1.31 & 1.44 \\
\hline Minimum height $(\mathrm{m})$ & 574.08 & 574.08 & 574.08 & 577.72 \\
\hline Maximum height $(\mathrm{m})$ & 1290.43 & 1279.65 & 1290.43 & 1290.29 \\
\hline
\end{tabular}

\section{DERIVATION OF POINT DENSITY INDICES}

The attributes of individual points of LiDAR point clouds are recorded in a LAS format. The format contains binary data consisting of a header block, variable length records, and point data [8]. Each point data record includes the XYZ coordinates, intensity, return number, number of returns, scan direction, and classification of the point. These attributes of point cloud are closely related to the geometry of laser scanning configuration and thus relevant to the point density of unit ground area. The spatial distribution of point density implies the properties of the land surface. For discriminating landslide and non-landslide lands, the types of point clouds for point density enumeration can be categorized as follows: (1) all points, (2) ground points, (3) single-echoes points or only-echoes points, (4) multipleechoes points, i.e. (first + intermediate + last) returns, (5) first-return points, (6) intermediate-return points, and (7) last-return points. Secondary indices can also be created by combining two or more types of point clouds, for example, penetration rate can be derived by the ratio of ground and all points denoting the fraction of points hitting the bare ground. For exploring the capability of point clouds for the detection of landslides, four types of point density with five searching radii are used in this study, including point density type of all points, ground points, only-echoes points, and multiple-echoes points. Comparison of them will be made to search for most descriptive ones for landslides.

\section{METHODS OF POINT DENSITY CALCULATION}

Point density can be measured by various approaches [1]. In this study, point density is measured by subdividing the surveyed area into grid cells, then computing the unit density of the number of points in a circle with certain searching radius centered at the cell center. A software application is implemented in this study to cater for the output grid size, searching radius, and type of points. This method is comparable to that by Crosby [9]. In this dedicated software application, the function of reading Terrascan PTC file for point class definition is also implemented so that various type of point density can be designated. Point density distribution of ground points is affected by the criteria and procedures of both automated and manual editing process. Nevertheless, point density except that of ground points is mainly decided by flight operation parameters including pulse rate, look angle, flight height, aircraft attitude, flight speed, strip overlap, terrain relief, and above-ground objects. Because average ground points is $0.75 \mathrm{pts} / \mathrm{m}^{2}, 1 \mathrm{~m}$ is selected for grid spacing. To cater for the effects of the uniformity of point distribution, ground surface undulation and land-cover types, five searching radii are used, i.e. $0.707 \mathrm{~m}, 1.414 \mathrm{~m}, 3.0 \mathrm{~m}, 5.0 \mathrm{~m}$, and $10 \mathrm{~m}$.

\section{RESULTS AND DISCUSSIONS}

After examination of the test results of the four types of points versus five searching radii, findings are as follows:

(1) Striping noise of point density map is obviously affected by flight speed and strip source as shown in Fig. 1 .

(2) Point density map of multiple-echoes point gives better contrast between landslide and non-landslide areas than any maps derived from other three types of point density, as shown in Fig. 2(B).

(3) For output of $1 \mathrm{~m}$ grid spacing, point density map with a searching radius of $1.414 \mathrm{~m}$ shows best result among all radii including $0.707,1.414,3,5$, and $10 \mathrm{~m}$. This result is subjected to the density of all points and ground points. A larger radius can not give better enhancement of landslides.

(4) Although the overall point density of only-echoes points of the whole study area is similar to that of multipleechoes points as shown in TABLE 1, a conspicuous contrast of landslide area is observed on the density map of multiple-echoes points other than that of only-echoes points. This is due to a high concentration of multiple-echoes points in forested land and most of bare grounds are covered by only-echoes points.

(5) Landslide feature is conspicuous in some part of the density map of ground points whereas it is vague in other parts. This is a consequence of the factors of penetration rate in different part of the area and the filtering process of non-ground points with both automated algorithm and manual editing. However, on the map of all points overlaid by ground points, landslides features can be enhanced for visualization. Nevertheless, commission errors are serious on this map, especially in those bare lands which are not landslides. These errors might be eliminated by slope gradient of ground surface in a later step.

\section{CONCLUDING REMARKS}

Point density maps derived from various types of LiDAR point clouds are tested and examined with scrutiny in this study for understanding the possibility of obtaining useful thematic maps from discrete points for landslide detection. Results show that some indices of LiDAR point-cloud 
density exhibit good contrast between landslide and nonlandslide areas and, thus, they can be used for deriving useful thematic maps. Four types of points are selected in this study with output grid spacing of $1 \mathrm{~m}$ and searching radii of $0.707 \mathrm{~m}, 1.414 \mathrm{~m}, 3 \mathrm{~m}, 5 \mathrm{~m}$, and $10 \mathrm{~m}$, respectively. Density map of multiple-echoes points with searching radius of $1.414 \mathrm{~m}$ gives the best result. All density maps except that derived from ground points are prone to striping noises due to flight speed and strip source. This has to be eliminated in a later study to explore the best capability for landslide detection of point density maps. Segmentation of OOA can be conducted to automatic classification of the density maps in further study.

\section{REFERENCES}

[1] P.T. Shih and C.M. Huang, 2006. Airborne Lidar point cloud density Indices. American Geophysical Union, Fall Meeting 2006, abstract \#G53C-0919. 12/2006. 2006 AGUFM. G53C0919S.

[2] X. Liu, Z. Zhang, J. Peterson, S. Chandra, 2007. The effect of Lidar data density on DEM Accuracy. In: MODSIM07 International Congress on Modelling and Simulation, 10-13 Dec 2007, Christchurch, New Zealand.

[3] A.M. Puetz, R.C. Olsen, B. Anderson (ed.), 2009. Effects of Lidar point density on bare earth extraction and DEM creation. in
Laser Radar Technology and Applications XIV. Proceedings of the SPIE, Volume 7323, pp. 73230I-73230I-8 (2009).

[4] G. Raber, 2003. The effect of Lidar posting density on DEM accuracy and flood extent delineation--a gis-simulation approach. NASA Affiliated Research Center (ARC), Department Of Geography, University of South Carolina.

[5] R. Dubayah and J. Blair, 2000. Lidar remote sensing for forestry applications. J. of Forestry 98(6), pp. 44-46.

[6] J.E. Means, S.A. Acker, B.J. Fitt, M. Renslow, L. Emerson and C.J. Hendrix, 2000. Predicting forest stand characteristics with airborne scanning LiDAR. Photog. Eng. \& Remote Sensing, 66(11), p. 1367- 1371.

[7] E. Naesset, 2002. Predicting forest stand characteristics with airborne scanning laser using a practical two-stage procedure and field data. Remote Sensing of Environment, 80(1) 88-99(12).

[8] $\quad 2009 . \quad$ ASPRS, Lidar_exchange_format http://www.asprs.org/society/committees/standards/lidar_exchang e_format.html.

[9] C. Crosby, 2007. GEON Points2Grid Utility Instructions. Access date: 2009-12-14. http://lidar.asu.edu/downloads/GEON_Points2Grid_Instructions.p df.

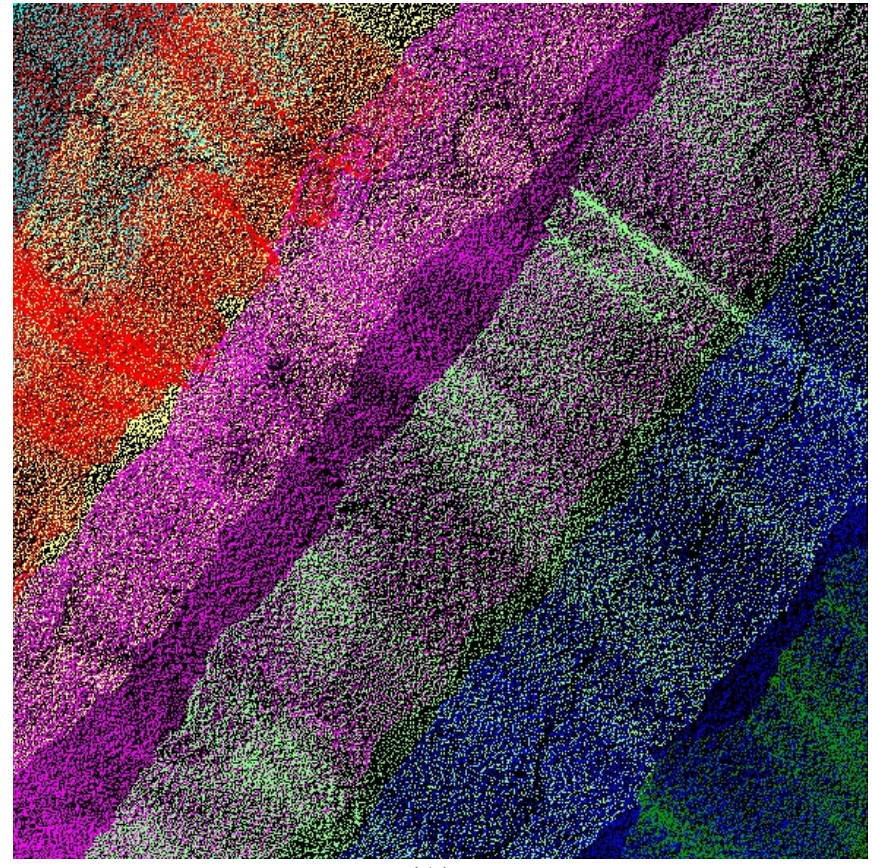

(A)

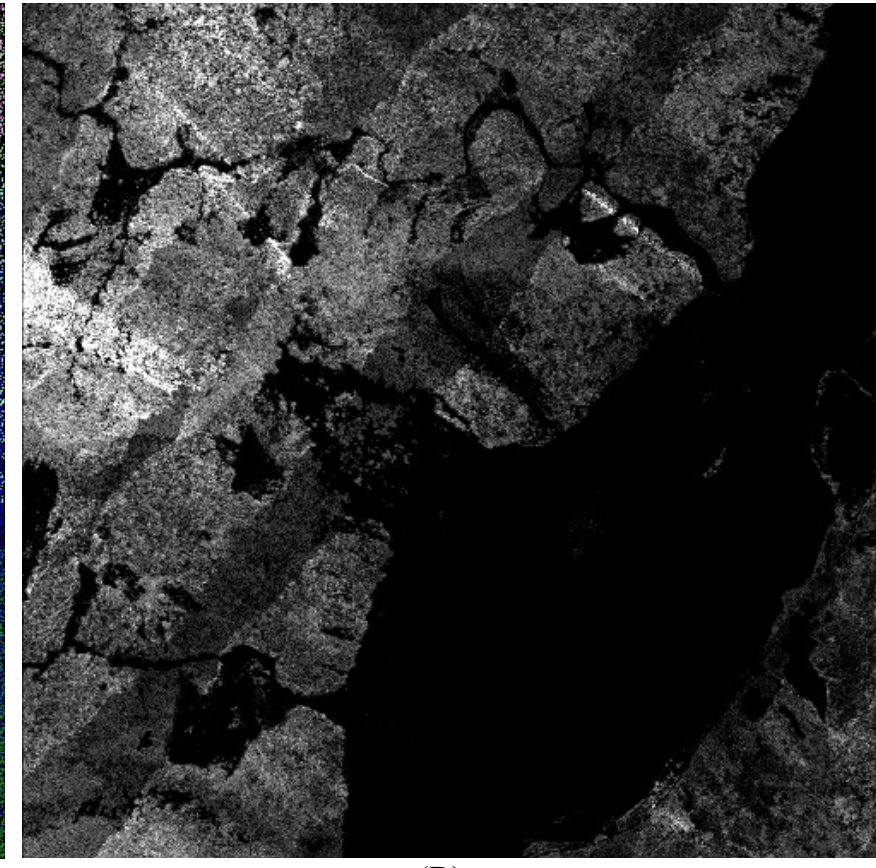

(B)

Fig. 2 Results derived from airborne LiDAR data of the study area. (A) Point cloud distribution with attribute of flight strip source ID. (B) Density map of multiple-return echoes with $\mathrm{r}=1.414 \mathrm{~m}$ and grid spacing $=1 \mathrm{~m}$. 


\begin{tabular}{|c|c|c|c|c|}
\hline & $\begin{array}{l}\text { Original point } \\
\text { clouds }\end{array}$ & $\begin{array}{l}\text { Density With } \\
\mathrm{R}=1.414\end{array}$ & $\begin{array}{l}\text { Density With } \\
\mathrm{R}=3.0\end{array}$ & $\begin{array}{l}\text { Density With } \\
\mathrm{R}=10.0\end{array}$ \\
\hline $\begin{array}{l}\text { All } \\
\text { points }\end{array}$ & & & & \\
\hline $\begin{array}{l}\text { Ground } \\
\text { points }\end{array}$ & & & & \\
\hline $\begin{array}{l}\text { Only } \\
\text { returns }\end{array}$ & & & & \\
\hline $\begin{array}{l}\text { Multiple } \\
\text { returns }\end{array}$ & & & & \\
\hline
\end{tabular}

Fig. 1 Selected results of four types of point density and their distribution under various searching radii with $1 \mathrm{~m}$ grid. 